\title{
DEVELOPMENT AS FREEDOM - AND AS WHAT ELSE?
}

\author{
Des Gasper ${ }^{1}$ and Irene van Staveren ${ }^{2}$
}

Prefinal version of a paper that appeared in 2003 in Feminist Economics, 9(2-3), 137-161. A prefinal version is also at http://repub.eur.nl/res/pub/21572/ The paper has been reprinted in: (1) Amartya Sen's Work and Ideas: A Gender Perspective, eds. B. Agarwal, J. Humphries \& I. Robeyns, London: Routledge, 2005, (2) Capabilities, Freedom and Equality, eds. B. Agarwal, J. Humphries \& I. Robeyns, Delhi: Oxford Univ. Press, 2006; (3) Amartya Sen: Critical Assessments of Contemporary Economists, ed. J.C. Wood \& R.D. Wood, London: Routledge, 2007, vol. 2, pp. 443-467. (4) Feminist Economics: Critical Concepts, Drucilla K. Barker and Edith Kuiper (eds), London: Routledge Major Work Series, 2009.

\begin{abstract}
To what extent can Amartya Sen's ideas on freedom, especially his conceptualization of development as freedom, enrich feminist economics? Sen's notion of freedom (as the capability to achieve valued ends) has many attractions and provides important opportunities to analyze gender inequalities. At the same time, Sen's recent emphasis on freedom as the dominant value in judging individual well-being and societal development also contains risks, not least for feminist analysis. We characterize the risks as an underelaboration and overextension of the concept of freedom. Drawing on Sen's earlier work and various feminist theorists, we suggest instead a more emphatically pluralist characterization of capability, well-being, and value, highlighting the distinct and substantive aspects of freedom, as well as of values besides freedom, in the lives of women and men. We illustrate this with reference to women's economic role as caregivers.
\end{abstract}

\section{KEYWORDS}

Amartya Sen, development, freedom, well-being, values, capability approach

\section{JEL CODES}

B4, D6, I3

\footnotetext{
${ }^{1}$ Des Gasper is Associate Professor in Public Policy at the Institute of Social Studies in The Hague. He works on topics in evaluation, policy argumentation, and ethics and development.

${ }^{2}$ Irene van Staveren is Senior Lecturer in Labor Economics of Developing Countries at the Institute of Social Studies in The Hague. Her Ph.D. dissertation at Erasmus University Rotterdam on the values of freedom, justice, and care in economics won the 2000 Gunnar Myrdal Prize.
} 


\section{INTRODUCTION}

Amartya Sen's Development as Freedom (1999) presents freedom as the central value in

development: "Expansion of freedom is viewed, in this approach, both as the primary end and as the principal means of development" (p. xii). He emphasizes what some people call "positive freedom," the capacity to be and do, rather than only "negative freedom," or freedom from interference, adding that sometimes this positive freedom depends more on the government than on markets. This view of freedom as capacity, and not only as absence of active interference, is an important commonality between Sen's work and feminist economics.

Sen's ideas on freedom have significantly influenced feminist development economics. He has addressed, for example, what Diane Elson and Nilufer Cagatay (2000) list as the three gender biases of macroeconomic policy: male breadwinner bias (keeping women financially dependent upon men), commodification bias (ignoring women's unpaid labor), and deflationary bias (cutting public expenditures on basic social services). In each case, he points to the importance of positive freedom for women and men alike: in his analysis of women's poverty at the household level, where he detects the breadwinner ideology as one of the causes of female poverty (Amartya Sen 1984a); in his writings on freedom from hunger, where he probes the results in times of hunger of the commodification of food (Amartya Sen 1989); and in his work on financial conservatism and the treatment of social services expenditure as "non-productive" (Amartya Sen 1998).

Throughout his career, Sen has also recognized values other than desire fulfillment and freedom, such as justice, democracy, and connectedness. In this paper, we try to assess to what extent Sen's more recent and increasingly strong emphasis on a language of freedom helps feminist economics. First, we will elucidate his conception of positive freedom, embodied in his capability approach and expanded in his book Development as Freedom, and determine its value for feminist economics. Second, we will present what we consider to be its shortcomings. As indicated by our title, this paper primarily addresses Development as Freedom, Sen's expansion of his earlier narrower statements of a capability approach. We are aware that the book addresses a wide audience rather than a narrowly scientific one. We will carefully examine some of its key 
formulations precisely because it has successfully reached such a large readership. Third, we will outline a complementary or broadened approach, building from Sen's own work on a variety of values. This approach more emphatically highlights and examines a plurality of human values and types of capability, as seen, for example, in Martha Nussbaum's “capabilities approach.” Freedom is perhaps best viewed as a particular family of values that must be embedded within other types of values, including those of caring. We will illustrate the critique and the proposal with reference to the unpaid care economy.

We suggest that Sen's focus on freedom provides an important space for the gender-aware evaluation of female and male well-being. He devised his capability approach, however, to refocus the evaluation of well-being and the quality of life (as compared to in conventional welfare economics). His approach is less adequate for other tasks, such as description, understanding, explanation, persuasion, and perhaps prescription, concerning well-being from a gender-aware perspective. Such tasks require a broadened picture and an alternative vocabulary. We suggest greater use of the term "capability" and less use of the term "freedom," which has many other associations, and the adoption of a refined vocabulary distinguishing the different types of capability. We also highlight that not all freedoms are good, and that it is necessary to distinguish among types of values and to consider how to variously promote them.

\section{SEN'S CAPABILITY APPROACH AND "DEVELOPMENT AS FREEDOM"}

\section{Negative freedom and positive freedom}

Many feminists have struggled for freedom for women, in particular freedom from patriarchy. This includes the freedom of having more options, ranging from access to abortion to access to education; the freedom of having better choices in their personal lives, such as the options opened by reliable contraceptives or (at work) by women's unions; and freedom from oppression in public as well as private life. Freedom has undoubtedly been, and remains, an important value in the women's movement and in feminist theory and analysis. 
Those in mainstream economics typically interpret freedom as "negative freedom," the absence of coercion and interference by others, specifically the absence of government "interference" in the market. This is often the meaning given to "free market": it is a "freedom-from," a freedom from constraints on one's choices in markets, leaving producers and consumers Free to Choose, as a book of that title by Milton Friedman and Rose Friedman (1980) terms it. This negative freedom is also accorded instrumental value as a means to promote well-being through individual choice, well-functioning markets, and GDP growth (see, for example, Milton and Rose Friedman's Capitalism and Freedom, 1962). In comparison, positive freedom, the ability to attain desired ends, is gauged by real income, albeit for many reasons an imperfect measure.

Gerald MacCallum (1967), among others (e.g. William Connolly 1983), has shown how statements about freedom implicitly use the form "Agent $\mathrm{X}$ is free from constraint $\mathrm{Y}$ on doing/being/becoming $Z$, which is an important value". Thus both aspects - constraining factors (Y, seen as "negative") and valuable attainable life-states (Z, seen as "positive") are present, whether explicitly or not. Arguments that positive freedom is an illegitimate addition to the idea of freedom are thus fallacious. Different conceptions of what are valuable life-states, and differences in the judgment (both explanatory and ethical) of what are constraints, will lead to different assessments of the degree of freedom that a person enjoys. If a woman is free from legal constraints on entering a public activity, but constrained by her commitments to care for old, young, or infirm family members, assessments of her freedom will reflect whether her participation in the public activity is considered important, and whether care is seen solely as a self-fulfilling choice and not also as a burden. The claim that the woman is "free" to participate reflects a focus only on the absence of legal constraints and active prevention, based on a view that there are no other ethically relevant constraints and on a voluntaristic conception of agency. For Sen, this limited interpretation of freedom is problematic: what matters is what this woman is really able to do and be.

Like Sen, feminist economists have criticized the predominant focus in economics on negative freedom (e.g., Julie Nelson 1996; Gillian Hewitson 1999; Graham Dawson and Sue Hatt 2000). They have argued that this implicitly idealizes Man as independent, already 
autonomous, rather than as a social being, someone socialized into the norms and values of a community, cared for by parents, and having personal bonds as well as rights and duties towards society (Marianne Ferber and Julie Nelson 1993). The assumption in mainstream economics that individual utilities are independent and not interdependent is one example of the masculine ideal of independence and autonomy (see, for example, Paula England 1993). Moreover, feminist development economists have argued that more negative freedom does not necessarily reduce women's poverty, increase their relative wages, or improve their share of consumption and decision making within the household (e.g., Naila Kabeer 1994; Diane Elson 1995). Sometimes more negative freedom even makes things worse for women, rendering justice or other values necessary.

\section{Sen's concern for positive freedom: the capability approach}

Amartya Sen $(1977,1987,1995)$ has placed his critique of a purely negative conception of freedom first within a wider critique of various components in mainstream economics, including its rationality concept and its utilitarianism, and second within an emergent alternative framework. He stresses freedom in the positive sense of ability to function well in life, in terms of ends that people "have reason to value". His ideas have contributed to the UNDP Human Development Reports, which provide broader measures of welfare and poverty than per capita GDP; these include the Human Development Index (HDI), the Human Poverty Index (HPI), and the Gender-related Development Index (GDI).

Sen's capability approach includes several features or aspects that need to be distinguished. Feature 1 is its broadening of the information specified as relevant for the evaluation of well-being and quality of life. Sen argues that more types of information are relevant than those considered by mainstream economics, which emphasizes only people's incomes, assets, and utility satisfaction. Centrally, we should also look at how people actually live and what degree of freedom they have to choose how they live.

Feature 2 is a family of new categories as a particular language for discussing these types of information. "Functionings" are components or aspects of how a person lives. A set (a vector or, more formally, n-tuple) of such functionings together make up a person's life. A person's "capability set" is the set of alternative vectors of functionings that she 
could attain - in other words, the alternative lives open to her, the extent of her positive freedom. For Sen, "capabilities" in the plural refers to the particular attainable functionings.

More specifically (and relevant for Feature 1), Sen argues that in looking at individuals' well-being, we should consider not only what they achieve for themselves ("well-being achievement") - in other words, their actual functionings - but also what they were free to achieve. We should assess this freedom in terms of what was open to them, both in terms of their own well-being ('well-being freedom') and of their actual values ('agency freedom'), including their values for other people. His primary category of capability is well-being freedom, which reflects the functionings that a person can herself attain.

Feature 3 concerns which categories and levels have ethical priority. In practice Sen seems often to use the following ranking when comparing spaces in which to measure development and equality: (1) capability, the set of life options a person is able to choose from, placed first because of the priority given to freedom; (2) functionings, or how a person actually lives; (3) utility, meaning feelings of satisfaction or the fact of preference fulfillment - ranked relatively low since preferences might be formed without much reflection or formed in situations of deprivation of information or options; and (4) goods/commodities, possibly placed last as a measure of well-being because people have different requirements. We could read the normative priority given to capability as an evaluative rule that "capabilities are more important than functionings."

If we instead or additionally read the normative priority given to capability as a policy rule to promote capabilities and then "let people make their own mistakes," this takes us to Feature 4, namely priority to capability as a policy rule, as distinct from an evaluative rule. For purposes of policy formulation, capability becomes an appropriate measure of how advantaged a person is, rather than a measure of the person's well-being itself, although it would contribute to the person's well-being (in the sense of the value of the person's functionings).

Feature 5 goes further: Sen ranks priority within the space of capabilities according to the criterion of what "people have reason to value." The question of how to 
operationalize this idea in multi-person situations leads us to Feature 6, stressed in Sen's more recent work: public procedures for prioritizing and threshold-setting as to which and whose capabilities are put first (e.g., 1999: 148).

The last feature - Feature 7-is less central, but periodically emerges in Sen's more applied work: the positing of notions of basic capabilities (basic for survival or dignity) and required minimum attainment levels. While these notions are ones that most people already find reason to value, to emphasize them explicitly helps to guard against cases where a person's reason leads instead to behavior that is damaging to the person herself or to others.

Sen's notion of positive freedom is applicable to men and women alike and is potentially sensitive to gender inequalities in social structures (for example, social security systems that depend on families having someone in formal employment), in norms (for example, female seclusion), and in economic institutions (for example, gendered job segregation). Using his capability approach, we can more clearly assess how women's freedom to live the lives that they value is generally less than men's freedom to do so: women have lower levels of education; they suffer reproductive health risks; their behavior in the public domain is often restricted by gender norms; and they suffer from labor market discrimination. These are a few of the many gendered "unfreedoms" that women face. Sen has vividly analyzed women's economic position, notably in writings discussed elsewhere in this special issue. His approach provides an orderly disaggregated framework that helps us look far beyond markets and commodities.

\section{The evolution of the capability approach into "Development as Freedom"}

Sen's capability approach has grown since the 1980s from a position in welfare economics to a wide-ranging development philosophy presented at length in his 1999 book Development as Freedom. The combination of his concerns for positive freedom and for replacing per capita GDP with human development indicators as evaluative measures seems to have led him in the direction of an increasingly unified conception of development as freedom. The term "freedom" now typically replaces "capability" in his work. He highlights freedom as the major means and end of development (1999: xii) and 
accords basic political and liberal rights "a general preeminence" (1999: 148). Over time, in assessing well-being and advantage, he has given more priority to capability seen as opportunity (the set of life options one has, what one can attain) and to the procedures of local prioritization within that space (Features 3 and 6 above), and he has deemphasized a universal specification of basic requirements (Feature 7). At the same time, Feature 7 remains present in some form: his empirical work on India and elsewhere reflects a consistent implicit set of what he considers to be ethically basic capabilities, yet he resists making an explicit list.

The labeling of development as freedom is perhaps in part strategic: Development as Freedom evolved from a series of lectures for the World Bank and seeks to influence audiences in mainstream development economics and seats of power (Des Gasper 2000). More than that, Sen's capability approach is centrally about the choice of an evaluative space: it argues that we should measure advantage by the extent of valued opportunities available to individuals. It contains only partial and somewhat implicit views about which opportunities people should have.

Sen certainly accepts that there are other values, notably justice in the distribution of resources, but he seems not to treat them fully on par with freedom. First, he seeks to incorporate many values within his freedom framework by talking about the freedoms to attain the things that one has reason to value. Second, it appears he wishes to leave other values open - free - for specification in each situation. In this respect, none of them appear to be treated on a par with free and reasoned agency as essential features of humanity. Instead his framework seems to be neutral towards, if open to, these other values. Third, because justice in the distribution of advantages depends logically on first clarifying the nature of advantage, he takes his framework of freedom to be the primary framework. He accepts that the capability approach has limits - for example, the limits to a principle of equalizing even basic capabilities, given that women have inherently greater life expectancy - but, as is clear from this example, he sees the limitations as relatively minor qualifications around a valid primary emphasis.

The next section takes a more critical view of how Sen has so far used and extended his concept of positive freedom. A concept put forward to improve the 
evaluation of well-being - by identifying the dimensions of functionings and (real) opportunity in contrast to felt satisfaction, goods obtained, or other measures of real income - may not suffice for wider purposes. For description, explanation, and prescription there are important additional building blocks, such as the concepts of sympathy and commitment, to be found in other parts of Sen's work and in the work of Nussbaum and others.

\section{SEN'S OVEREMPHASIS ON FREEDOM}

\section{An underelaborated and overextended notion of freedom}

Sen's notion of freedom remains, in some key respects, under-characterized in Development as Freedom. He writes extensively about "unfreedoms" and it becomes clear what the "bads" are when freedom is lacking. But we do not get a clear picture of the content of freedom itself, including the varieties, skills, dispositions, and preconditions involved; it is instead an abstracted umbrella category.

Sen sees freedom as the dominant evaluative space for human well-being, a space spanning many different ends. He uses the word when indicating the relevance of various goods in life, such as knowledge or health (freedom from ignorance, freedom from illness). All the capabilities that human beings could acquire are to be understood as freedoms. This inevitably makes the notion of freedom broad, vague, and potentially confusing. It becomes easy, for example, to confuse the "freedom to survive" with the freedoms that survival brings, as Paul Seabright does. ${ }^{1}$ There is also no longer a highlighted distinction between the value of autonomous agency and all the opportunities to achieve other values that may be provided through such agency. Those two aspects of positive freedom deserve separation. Bernard Williams (2001: 7-8) adds:

This ... idea of liberty as ability or capacity ... has an obvious disadvantage: we already have a concept of ability or capacity, and on this showing "liberty" or "freedom" turn out boringly just to be other names for it. More importantly, it misses the point of why we want these terms in the first place. 
We will come to Williams's point in a minute. For the moment, let us consider whether Sen's generalized language of freedom is the best way of directing attention to various important distinctions. His language needs at the least careful handling in order to avoid misuse. As with any language, the perspective it gives can be corrected by qualifiers and reminders, and Sen himself is well aware of necessary qualifiers. But, as with his use of the terms "entitlement" and "capability", so with his use of the term "freedom": there is potential for confusion since the word is already well-established in everyday language, and he is proposing that it now be understood in a specific and distinct way, diverging from much or most common usage. His concepts of "entitlement" and "capability" provide fruitful distinctions but have been subject to misunderstanding due to the labels themselves (Des Gasper 1993, 2000, 2002). Similarly, in the case of "freedom," we need more differentiation of terms. Having taken the everyday term "capability" to mean not skills but attainable options, Sen has seemingly now downgraded it for communicating to a broader audience and turned to "freedom" as a more evocative term. But that term comes with a lot of other baggage.

In political philosophy, freedom stands out from other values precisely because of its distinctive ethical meaning - as expressed, for example, in the French Revolution maxim "Liberté, Egalité et Fraternité". In a volume on the meanings and normative roles given to freedom in economics, Serge-Christophe Kolm has tried to disentangle the meanings of freedom from other values, emphasizing that freedom is related to individual agency as a combination of will-freedom, namely willful or voluntary acts, and reason-freedom, implying autonomy, as "one's choice of one's principles of choice" (Serge-Christophe Kolm 1998: 22). He argues that in its most common conception, freedom is choice and intentional action. Hence, he recognizes the values of freedom to be related to the self, to autonomy, and to independence, not only as "self-choice, self-determination, self-causation, and self-creation" (Kolm 1998: 28), but also as a condition for "awareness, respect and esteem of oneself, for dignity and for pride" (ibid.). These and related freedom values appear repeatedly in the other contributions to the volume in which Kolm's study appeared (Francois Laslier, Marc Fleurbaey, Nicolas Gravel, and Alain Trannoy 1998) and in a 
monograph on the value of freedom in political economy by Alan Peacock (1997).

Like Kolm, Williams emphasizes that freedom is about acts, about both doing and the capacity for doing, hence the importance of freedom from coercion and constraints. He goes on to refine this concept of "primitive freedom" (2001: 7). First, he distinguishes five types of coercion and constraints, ranging from force and threats through to the by-products of other arrangements that prove to structurally disadvantage a group of persons (2001: 8-9). For feminist analysis, this is a helpful categorization: gender-based unfreedoms can be found in each of these five categories, ranging from explicit prohibitions for women compared to men, like a prohibition against doing wage work in some regions, to implicit and invisible gender norms, such as those defining certain tasks as masculine and others as feminine.

Second, Williams notes how a "political concept of freedom" emerged historically. It arose to distinguish between, and object to, particular types of constraint, and thus to appeal to a political authority for the removal of such constraints. These are the constraints deemed both obnoxious and humanly imposed (whether intentionally or unintentionally but culpably); plus those not created by humans but culpably not removed by them. He calls the associated political value "liberty". Its justified scope is of course disputed. Many people simply use the term "freedom" for this political value, too.

We thus can see the importance of distinguishing rather than merging concepts within the freedom arena, and of being sensitive to the "complex historical deposit ... of the idea of freedom" (Williams 2001: 4), its intense historical connotations. Sen is right to emphasize that capability is a language of freedom and a legitimate use of such language, not an illegitimate extension beyond "negative freedom". He seeks to recapture Adam Smith's mantle from the Friedmanites and others in the cause of a humane economics. But in our view, his undifferentiated language of freedom - as if the stream of thought of the Friedmans and kindred spirits has not existed and does not draw on some powerful elements of the historical deposit - is not enough for this.

Given these preexisting common understandings of freedom, the degree of emphasis on freedom in Development as Freedom risks leading some people to ignore contributions to well-being that are not part of one's autonomy and independence, but rather of their 
opposite. The intense focus on freedom may neglect evaluations of well-being in terms of social relations and personal relationships, which are important sources of women's wellbeing as well as a result of women's joint efforts to enhance others' well-being. Using a language of freedom in connection with almost every value ("freedom to survive", "freedom from illness", etc.), rather than more strongly emphasizing development as relating to a multitude of distinct human values that demand separate attention, might obscure the substantive contents of specific values. We shall now investigate the importance of highlighting specific values, using examples from Sen's own insightful work on democracy, respect, and friendship, to extend his capability approach.

\section{The importance of other values}

The "Development $\underline{\text { As }}[$ not $\underline{\text { Is}}]$ Freedom" formulation leaves space for asking, "And development as what else?". Sen packages a great deal into his notion of positive freedom. He can bring values other than those related to the independent self under his language of freedom, since he formulates freedom in terms of the ability to effect whatever one has reason to value. When our agenda is not only evaluation, but also explanation and prescription, however, a more differentiated language becomes essential. We will consider here the values of democracy, respect, and friendship.

In his work on poverty and famines (Amartya Sen 1981a), Sen argues that democracy, apart from being valuable in itself, makes a major instrumental contribution, in particular in preventing famines. Democracy is not merely a value which holds that people should choose freely, but a value that sometimes challenges freedoms (defined as willful and reasoned choices). And it is sometimes called upon to discipline freedoms when these allocate food to where the purchasing power is, rather than to where it is most needed. In Sen's language of development as freedom, the need for democracy to discipline freedoms (such as the positive freedom to speculate in basic commodities, especially in times of shortage) might become obscured, even though that is far from Sen's intention or own usage. We need to be clear that while we have good "reasons to value" some freedoms, we also have good reasons to disvalue some other freedoms. The freedom to make a fortune by hoarding grain or (to use or adapt examples from Martha 
Nussbaum in this volume) the freedom to pollute the environment or to buy political influence are not freedoms that society has good reason to value; yet they are freedoms. Nussbaum's paper in this volume makes the point forcefully.

Prioritization of poor people's subsistence and survival over affluent people's valued freedoms (as in Feature 7 above) might have to be rooted in a nation's constitution or bill of rights. Otherwise, a language for promoting valued positive freedoms could be used or misused to cloak massive injustice. In hierarchical polities, affluent people's freedoms could be de facto prioritized, despite elaborate formal democratic procedures to prevent this (as in Feature 6). Though all priorities supposedly would come from a locally specified process of debate, consultation, and decision, the outcome in practice could be harshly elitist, thanks to the power of wealth, established authority, and differential access. The capabilities and functionings of one gender, for example, might concern public officials more than those of another gender, even when reasoning from a human development perspective (as Thanh-Dam Truong 1997 has argued). For this reason, in her version of the capability approach, Nussbaum sometimes adds a Rawlsian difference principle and stresses a constitutional specification of the rights to basic capabilities. Other responses having the same function are also possible. While none is a cure-all solution, they have an important role to play.

Another value that is different from freedom (defined as personal independence) is respect. Again it has both independent and instrumental significance. Poverty is characterized not only by a lack of money or material resources but equally by a lack of respect from others (Amartya Sen 1984b). Being respected is a significant factor in an individual's success in growing out of poverty, and respect in turn involves and affects the capabilities of self-esteem and confidence. Self-esteem appears frequently as a vital first step for women to improve their well-being - for example, through education or by joining women's NGOs. Interestingly again, an all-encompassing unified language of freedom may not help bring the value of respect to our attention. Women may be free to join a credit program, but without the self-confidence to engage in a business activity, they will not do so. When Sen lists sources of interpersonal variation in well-being in Development as Freedom, self-esteem and related learned capacities are conspicuously 
absent (Sen 1999: 70-1, 88-90; see also Gasper 2000).

Friendship appears as another important value having its own set of skillcapabilities. Sen has shown the instrumental importance of friendship - provided we hold it as an independent value. His example features Donna, who is committed to save the life of her friend Ali, who she knows is likely to become a victim of a planned racist attack (Amartya Sen 1981b). She goes to the police, who dismiss Donna's story as fantasy. Although Ali is entitled to police protection, he does not get it. An alternative for Donna would be to break into the office of someone who happens to have the information where Ali is, but that would violate the law as well as the other person's privacy. In a utilitarian calculation, then, the benefits from the attack to the group of attackers might be greater than the costs to just one person, hence the principle of utility maximization might not help Ali. Sen implicitly suggests in this story that the only value available to Donna that might save her friend Ali is her friendship. Committed as she is to her friend, she is determined to find a way to save him, although it will cost her time and effort and she runs the risk of becoming the next target of the attackers. In Sen's language, this is "commitment," which means that a person follows values whose fulfillment does not raise her own satisfaction. In contrast, "sympathy" means that a person's satisfaction is favorably affected by an increase in another person's well-being.

While the case could still be described using Sen's language of capability as positive freedom, that does not seem the best way. It is not Ali's free agency nor his rights but his close relationship with Donna that will help him eventually to get out of the threatening situation. Friendship is a value that in a particular case contributes more effectively to furthering individual well-being than the value of freedom (as personal independence) is able to do. While Sen acknowledges this in his example of Donna and Ali, he provides no clear place for friendship in his freedom approach.

\section{Achieved functionings, internal freedom, and personhood}

The dominant language of freedom might sometimes hinder us from attending to important matters. A conception of human development, as promoted by the UNDP Reports, for example, needs more than one value. Freedom is not enough, even in a version 
that refers to other values and is supplemented by a justice criterion. Capability is only one relevant space in an evaluation, even for the welfare economics exercise of judging the position of a responsible adult, and it is relevant for adults more than for children. We are not interested only in whether a girl has the potential, the positive freedom, to be healthy, but also in how healthy she is. We are not interested only in whether India has the potential to educate all its girls, but also in whether it actually does so. We are interested both in how far a society enjoys the possibility of fulfilling important values and how far it fulfills them in practice. In the Human Development Index, two of the dimensions - knowledge and longevity - do directly reflect valuable functionings and not only the potential for these. That we must often measure capability via the proxy of functioning has been fortunate, for we need to measure functionings too if we are to evaluate human development adequately.

Sen provides space for other values through his flexible phrase "what we have reason to value". "To value" is in his usage something more considered, more reasoned, than a mere preference, urge, habit, or whimsy, and to underline this he adds the phrase “have reason to." Sebastian Silva Leander (2001) suggests that Sen's capability notion should more clearly distinguish between two types of freedom: having attainable options, which connects with Immanuel Kant's concept of external freedom, and being able to make independent well-reasoned choices, which connects with Kant's concept of internal freedom. Such internal freedom is central in Kant's conceptions of humanity and progress. Sevèrine Deneulin (2003) concludes that Sen's approach says too little about how to assess and promote the capability for freedom itself, other than by mentioning access to good information.

Lawrence Hamilton (1999) argues that Sen holds back from a more substantive theory of values and needs because of excessive faith in a thinly specified version of practical reason. ${ }^{2}$ This version presumes that persons are rational and nonvicious, at least if they are provided with information, basic training (thus the theory applies to adults), and opportunities for public debate. These requirements are important but not sufficient for reasonableness. Sen, in any case, assumes and advocates a viable liberal democratic state, where basic rights can be articulated, operationalized, and respected for every group in society. But in a market-oriented, money-dominated world, his capability approach faces 
some risk of subordination to what comes out of such market- and money-dominated processes, unless it is combined with a richer language for analysis and evaluation. If partnered by richer pictures of personhood, the capability approach might help in identifying and confronting consumerism. In their absence, its emphasis on increasing the range of choice can be distorted into a defense of consumerism. ${ }^{3}$

The "development as freedom" formulation thus needs to be embedded in a broader picture of human values and with more attention to "internal freedom". In the next section, we will trace a move from a relatively thin and unitary picture of persons and values to a more complex and plural picture, drawing in part on Sen's earlier work, to give a more adequately contextualized concept of freedom.

\section{A SITUATED AND MORE SUBSTANTIVE NOTION OF FREEDOM}

In this section, we consider responses to the underdefinition and overextension of Sen's notion of freedom. As a remedy for freedom's underdefinition, we outline aspects of the thicker notion presented by Martha Nussbaum and others. As a remedy for the concept's overextension, we emphasize the nonhierarchical relationship among a plurality of values that together make up well-being or development. We will illustrate this in the subsequent section, with reference to the values of caring and to women's role in providing unpaid care.

\section{Combating underdefinition with Nussbaum's help}

Sen presents a richer picture of persons than that in 'rational economic man'. He notes the possibility of what he calls sympathy and commitment; and he notes preferences about preferences, as part of reasoning about preference. However, the picture remains predominantly one of choosers who reason, rather than one of more richly scripted actors. The conception of freedom as opportunity is an abstract one about possibilities in a given context, not a substantive one about psychic states, capacities, and propensities.

In defining capability as positive freedom, Sen has built on a usage that is perhaps less common in everyday language. More common is the sense of capability as a skill or

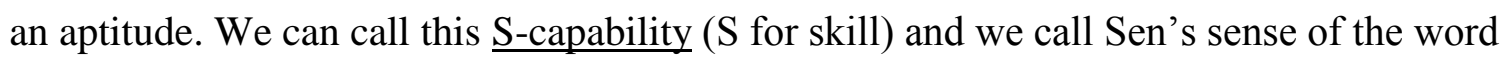


O-capability ( $\mathrm{O}$ for attainable options and opportunities). Nussbaum elaborates the Scapability sense, which she calls "internal capability" (she uses "external capability" for what the person can attain). This skills sense is essential in description and explanation, and thus also for more grounded prescription. An opportunity set is not a picture of personhood or agency. Theorizing capability only as attainable opportunities and not also as skills and traits will limit us in building a more structured picture of personhood and agency. It can lead to underemphasizing key requirements for "free choice" and underestimating the extent of deprivation. We agree with David Crocker (1995: 182) that "Sen's theory of actual freedom would be more comprehensive and humanly nuanced if he followed Nussbaum and added internal powers to external opportunities and viewed humans not only as capable but as in need of nurture in a context of neediness."

Because Nussbaum gives a richer and a more gender-balanced picture of thought and emotion, and of influences on them, she is stronger than Sen on meanings and action, including on emotional development and making use of freedom. Her approach may have greater potential for helping us understand the requirements of action and for motivating it (Martha Nussbaum 2000, 2001; IDEA 2001).

The broader definition of capabilities, distinguishing between opportunities and skills, makes her approach less abstract than Sen's and closer to the texture of daily life. She proposes ten sets of priority capabilities under the headings: (1) life; (2) bodily health; (3) bodily integrity; (4) senses, imagination, and thought; (5) emotions; (6) practical reason; (7) affiliation, or "Being able to live with and toward others (and) having the social bases of self-respect and non-humiliation..."; (8) other species, or "Being able to live with concern for, and in relation to, animals, plants and the world of nature"; (9) play; and (10) control over one's environment (Nussbaum 2000: 79-80). This list of capabilities reflects a combination of skills and opportunities. Some concern the internal capabilities of a person, like emotions, which require training and maturing, but afterwards do not depend much on outside resources - unlike, for example, bodily health. They cannot all be well understood as freedoms in the usual sense. A capability for affiliation is only in part a freedom, as in the ILO Convention specifying workers' right to freedom of association. Affiliation depends also on intimate relationships between 
people, rather than only on their personal autonomy to engage in relationships with others.

Nussbaum notes, "I am not pushing individuals into the function: once the stage is fully set, the choice is up to them" (2000: 88 ; emphasis added). But this choice is embedded in an individual's social networks, like families and communities, and "the capabilities are an interlocking set; they support one another, and an impediment to one impedes others" (p. 294).

Nussbaum stresses minimum thresholds for individual well-being. Each citizen should enjoy those minimum levels of capability before those who have the means to do so go on to attain high levels of full freedom. In some of her writings, she has even proposed a Rawlsian difference principle: inequalities in capabilities can be tolerated as long as these differences lead to more people attaining the minimum threshold (Martha Nussbaum 1995: 87).

This approach to capabilities moves away from a dominant focus on the language of freedom and towards a greater emphasis on an interlocking set of values, reflected in a diversity of capabilities. For women, Nussbaum notes, this view offers a way out of the dichotomy between exclusive individual freedom, on the one hand, and traditional women's roles, on the other. Nussbaum's approach of using a set of plural capabilities promises that "we are not forced to choose between a deracinated type of individualism, where each person goes off as a loner, indifferent to others, and traditional types of community, which are frequently hierarchical and unfair to women" (Nussbaum 2000: 289).

Nussbaum's approach also enables us to transcend the common dichotomy of masculine and feminine attributions of human agency (reason versus emotion, calculation versus interpretation, or independence versus dependence). She goes beyond such dualities to argue for concrete human capabilities, addressing not only individualistic needs but also social and interpersonal ones. Her approach is more open to highlighting community and family as essential spheres.

True, Nussbaum's capabilities approach has its own limitations. It explicitly acknowledges that it is oriented to the design of political constitutions and policy 
frameworks rather than to the details of poverty research and administration: it does not indicate how to measure the various capabilities and cannot easily be employed in a quantitative cost-benefit analysis (Martha Nussbaum 1999: 236). And although her list of ten priority capabilities has evolved and improved over many years of debate, and contains considerable room for multiple versions and different local specifications, it will always be contestable (Fabienne Peter 2001). It should be understood not as a universal blueprint, but as an exemplar of an appropriately substantive agenda for the discussion of priorities and basic rights - as a set of criteria for "a decent social minimum in a variety of areas" (Nussbaum 2000: 75). The list can serve as a framework for dialogical investigation. A helpful set of papers on such issues and on her approach's contributions and possible limits is found in IDEA (2001). ${ }^{4}$

\section{Combating overextension: highlighting other values}

A variety of authors, such as Michael Walzer (1983) and Elizabeth Anderson (1993), suggest that freedom be seen as just one relevant sphere among others. For these authors, freedom is distinct from, and even incommensurable with, other values. This notion of freedom ensures a recognition of the importance of other values and implies that a more modest weight be given to freedom, here no longer viewed as an overarching or dominant characterization of development. The more clearly defined and the better distinguished it is from other values, the more meaningful becomes the role of freedom as a value operating in economic processes.

Irene van Staveren (2001) has tried to link the idea of a range of distinct values to specific skill-type capabilities phrased in terms of these respective values. She emphasizes three spheres of values in economic life - freedom, justice, and caring. Each encompasses a variety of incommensurable values that are, however, related to one another. Whereas Sen talks of freedoms to attain goods that we find reason to value and of justice in the distribution of those freedoms, a conception that adds caring to these two spheres provides a more substantive characterization of values. This in turn is more helpful for description, explanation, and prescription.

Freedom is seen here as a family of values related to the self and to what one can 
do, hence to individual agency. Next to these self-related values of freedom lies a sphere of public values of justice, including values of respect and solidarity, as well as a sphere of interpersonal values of caring, which characterizes relationships between people - for example, expressing trust in a community and taking responsibility for family members. To enhance values of freedom, individuals may acquire capabilities related to free choice, autonomy, self-esteem, and most of all, individual agency. But having freedom of choice, for example, will not be particularly helpful for someone who is in mourning because his parents have died. The person's well-being in that situation will benefit more from friends who comfort, as well as from joint participation in a funeral ceremony that is appropriate for the cultural context. Hence, different values require different capabilities. Values of justice, for example, are reflected in capabilities for solidarity and respect for other human beings as well as animals and the natural environment, whereas values of caring emerge in personal relationships expressed by capabilities of trust and trustworthiness, loyalty, and responsibility.

These three spheres are not independent from each other: freedom enables justice and caring, but also constrains them. In turn, the values of justice and caring are related to each other and to freedom. The values should be understood as interdependent, just as Nussbaum argues in relation to her set of priority capabilities: one cannot be well attained without the others. The values can ideally be thought of as continuously balancing each other, at the macro level as well as at the micro level of the individual. Too much of a burden of caring labor will limit women's freedom, for example. But too much freedom, in terms of independence from a household and community, will limit an individual's well-being in times of scarcity or illness: others will not feel responsible for helping someone who has refused to contribute to mutual support networks in the past. An exclusive pursuit of freedom thus diminishes opportunities to receive care when needed.

\section{WOMEN'S ROLE AS CAREGIVERS}

Let us consider women's role as unpaid caregivers for the family and community, a role assigned to women worldwide. How far can the issues arising from this be understood 
within Sen's framework of development as freedom?

In Chapter 8 of Development as Freedom, Sen argues for gender policies that focus on women's capability and agency rather than, as is conventional, on women's disadvantaged levels of functionings. For him, a focus on women's agency - their formation, pursuit, and attainment of goals - often implies promoting paid work outside the home for women, giving them independent incomes. "So the freedom to seek and hold outside jobs can contribute to the reduction of women's relative - and absolute deprivation" (Sen, 1999: 194). Paid jobs help women to become financially independent from their husbands and fathers, and to make their own choices in consumer and financial markets. Feminist economists have underpinned this relationship between paid employment and well-being with their critique of the model of the unitary household and with analyses of women's bargaining position. Sen adds that the freedom that goes with paid labor brings important values for women, such as self-esteem, dignity, and autonomy. And he elaborates the effects of greater bargaining power in and outside the household: "Freedom in one area (that of being able to work outside the household) seems to help to foster freedom in others (in enhancing freedom from hunger, illness and relative deprivation)" (1999: 194).

However, women's working lives include a large share of unpaid labor, making up a major part of the care economy (see, for example, Nancy Folbre and Julie Nelson 2000). This unpaid care economy produces goods and services on a vast scale for the benefit of others (households, family members, and communities). Estimates of its monetary value, on the basis of the opportunity costs of women's time, range from 6 percent to 55 percent of GNP as presently calculated (Marga Bruyn-Hundt 1996: 51). The unpaid care economy is qualitatively essential, since although some of the goods and services produced have market substitutes, many do not. If women did not care for children beyond the level of care provided in child care organizations, for example, the market would hardly do it in place of them. Similarly, it is hard to buy friendship or understanding and comfort during mourning. In addition, caring labor produces more than just goods and services: it simultaneously generates and cherishes a set of values interpersonal values of belonging and sharing. 
Caring values include responsibility, loyalty, and generosity. Many women value caring and find much meaning, even part of their identity, in caring for others. They see its complementarity with market production and recognize its important contribution to the well-being of those cared for. But caring should not be romanticized. Just like paid labor, it can not only bring benefits but also involve costs, such as pressure on one's health. Caring is a burden to caregivers; it takes time, energy, and emotional commitment, as well as other resources. These burdens are, as Nancy Folbre and Thomas Weisskopf (1998) note, largely assigned to women, based on traditional gender norms, and backed by power and coercion. Lee Badgett and Nancy Folbre (1999: 316) have argued that the far greater share of time that women spend on caring, compared to men, could be characterized as a "socially imposed altruism" placed on the givers. Nussbaum (1995) points out how complex is the relation between caring and women's well-being, and the pains as well as material and emotional benefits that go with intimate relationships, particularly when a relationship is characterized by dependency.

Hence, the role of women as caregivers is complementary to market production. It involves the production of some goods and services that markets are unable to provide, and reflects values of belonging and sharing that are different from those of freedom, which Williams and Kolm have described instead as values of independence and autonomy. Caring involves a burden, which often limits women's capabilities related to freedom, such as their financial independence and their self-esteem as workers. Care also affects the capabilities and functionings of both the caregiver and the care receiver, with a positive effect on the care receiver's functionings, but often lowered functionings for the caregiver. Care involves time that goes without compensation, and it generally ties the caregiver to the care receiver, often in and close to the home.

More goes on, however, in the activity of caring. As a practice between caregiver and care receiver, it generates caring capabilities in individual agents. Such capabilities represent intangible, informally acquired skills and values, including (1) attentiveness to the needs of others; (2) acceptance of the responsibility to address these needs even if they do not arise from consequences of our own actions; (3) competence in addressing these needs well; and (4) responsiveness of the care receiver to the caregiver, as a 
feedback into the caring process (Joan Tronto 1993).

Just as capabilities like self-esteem and self-confidence contribute to the functioning of the economy, so do the capabilities of caring. Caring capabilities in economic life strengthen economic processes by generating trust (both trusting and trustworthiness), encouraging taking of responsibility for the externalities of one's market behavior, enhancing communication (through engaging in human relationships), and improving interpretation of others' economic position (their resources, skills, bargaining power, demand, etc.). Without such capabilities, economic processes would be characterized by higher transaction costs, negative externalities, and more volatility and uncertainty in production, investment, and consumption levels (Irene van Staveren, 2001).

Hence, at the micro level as well as at the macro level - in households and in communities - caring contributes to people's capabilities, their functionings, and in the end, their well-being, although the distribution of costs and benefits can be very uneven. On average, women undertake about three-quarters of the caring work in the world, while at the same time men do most of the paid work and earn the larger share of income (UNDP 1995).

Sen's framework of development as freedom places (and rightly so) much attention on increased freedom for women through paid employment. However, if women all engaged more in paid employment (with increased labor force participation in numbers of women as well as in hours per woman), who would do the unpaid caring? In all likelihood, either women would be overburdened with a double workday, or many caring needs would be left unattended. Hence, there may sometimes be a trade-off between women's freedom and care. And as is apparent when women do not undertake paid labor but specialize in unpaid caring labor, there is a trade-off between their freedom and the freedom of those cared for, which raises a question of justice.

It might be possible to increase women's labor force participation while reducing the impact on care by redistributing some caring work to men. For the sake of women's functionings, this is essential. A more balanced distribution of paid and unpaid labor between men and women would produce another benefit in its generation of a wider set 
of capabilities for both sexes: both freedom-type capabilities, such as independence and self-esteem, and caring-type capabilities, like responsibility and affection.

But a view of development as freedom - as centering on autonomous, willful, and reasoned acts - would not readily promote such a redistribution of unpaid caring labor from women to men. Of course, caring for a child will further the child's freedom, but that is not the problem posed by many men's refusal to be more actively involved in caring for their children. The challenge is to convince men to assume their fair share of household work (such as child care) and community work. It is hard to see how to do this by referring to someone's individual freedom: how can we convince men to do more unpaid caring labor in terms relating to an increase of freedom? As women know from experience, housework and child care may bring various satisfactions, but they do not bring much freedom. It is the lack of freedom that goes with caring that led Sen to emphasize paid employment in the first place.

Now, Sen's language of development as freedom does not treat freedom as meaning only personal independence. It instead refers to the ability to attain whatever one finds reason to value, which can be stretched to say that caring for the infirm and needy, based on sympathy or acceptance of duty, represents a use of a freedom to further an accepted value of caring for others. But in addition to the danger of misreading this "development-as-freedom" language, given the entrenched other uses of "freedom", this formulation is not helpful for thinking about the content of a value of caring, both how it arises and how it might be promoted. We should highlight the distinct psychological contents of different values and name them appropriately.

An alternative to Sen's unified language of freedom would lie in emphasizing the plurality of development, beyond only freedom. This means highlighting not just values related to the self, values that increase one's independence and autonomy, but also values related to relationships with others, as well as values related to fairness of distribution. The claims of justice themselves may be better grounded and more persuasive (forming a basis for accepted duties and not only claimed rights) through this more substantive attention to personhood and to experiences of care. 


\section{CONCLUSION}

We have analyzed the focus in Sen's capability approach on freedom, presented as the principal means and end of development. ${ }^{5}$ Sen's notion of capability and positive freedom proves to be more useful for gender-aware analysis and the study of women's well-being than the neoclassical ideas of utility and negative freedom. His concern with autonomous agency helps us to analyze women's freedom to live the lives they have reason to value and to identify the constraints to this freedom.

But in comparison to his earlier work, where he analyzed a wide variety of human values next to freedom, Sen's increased emphasis on an umbrella conception of freedom appears less sufficient for the tasks of describing, explaining, motivating, and then developing policy recommendations. This is especially so for the economic roles of women that are tied to different values, such as values of solidarity or connectedness.

We identified two main shortcomings in the treatment of "development as freedom" in his 1999 book. First, we noted an overextension of the emphasis on freedom, to the extent that all capabilities that women and men could acquire are now to be described as freedoms, regardless of their specific content. Some important values, such as those associated with friendship, respect, and care, cannot be adequately understood in terms of individual freedom.

Second, we found its concept of freedom to be under-elaborated, since it does not sufficiently distinguish between autonomous agency and the variety of values that may be promoted through such agency, or between capability as a set of opportunities and capabilities as skills and capacities that can be nurtured. We agree with Ingrid Robeyns (2001) that Sen's capability approach in general is deliberately underspecified, and thus risks being coupled with questionable, not least gender-biased, partners. The risk increases if the approach is perceived as a general philosophy of development -- unless it is refined and complemented. Sen tries to recapture the language of freedom and the authority of Adam Smith from those, like Milton Friedman, who have tried to claim them exclusively for market libertarian viewpoints. But his highly generalized use of "freedom" may come at the cost of downplaying some necessary distinctions, including 
those between desirable and undesirable freedoms, and between freedom and other values. Development may be better described as at least comprising freedom and justice, and more enlighteningly as involving also the growth and maintenance of the value of caring for others.

To address these shortcomings, we have argued for an alternative language that lays more explicit stress on other values that are as important as freedom (seen as choice and intentional action), values that are also means and ends of development. This requires a recognition of different capabilities as valuable in their own right, not simply as examples of freedom. Freedom - as choice and intentional action - instead should be emphatically embedded within a fuller picture of other values and needs. This suggestion draws on Sen's earlier work in which he shows the contribution of values like democracy, respect, and friendship to well-being and development. These varied values and the corresponding valuable capabilities require more specific and substantive designation, investigation, and support than is available in the generalized language of "development as freedom." Here we endorse aspects of the work of Nancy Folbre, Julie Nelson and Martha Nussbaum, among others. Without this sort of more substantive theory of personhood, the language of freedom in the capability approach could be co-opted in questionable and gender-biased ways.

We suggest moreover that promotion of individual well-being, in particular the well-being of women, which in so many respects lags behind that of men, benefits from a recognition of minimum required levels -- or thresholds, as Nussbaum terms them -- for some priority capabilities and functionings. Everyone's attainment of minimum levels for these important aspects would be prioritized over the freedom of those who have already reached higher levels of well-being.

Finally, we propose that such a pluralist understanding of capabilities would help to better acknowledge the contribution of women as caregivers as well as the constraints imposed by this role on women's freedom. On grounds of both personal development and justice, it then becomes possible to argue for some redistribution of caregiving from women to men - which would advance both women's freedom and men's capability of caring. 
ACKNOWLEDGMENTS - We have benefited from comments by three anonymous referees and by Jane Humphries, Ingrid Robeyns, Sabina Alkire, and other participants in a workshop in Oxford held on September 10-12, 2002, notably Amartya Sen, Martha Nussbaum, and especially Bina Agarwal. The usual disclaimer applies.

\section{ENDNOTES}

${ }^{1}$ Paul Seabright (2001: 42) remarks: “. . . the wish to see freedom as the fundamental value underlying every other even leads Sen at one point to talk about mortality as a denial of 'the freedom to survive.' Well, yes, one can call it that, but is it really illuminating to suggest that what matters about being dead is the lack of freedom that goes with it? Being dead is also bad for the health and has a significant statistical association with dropping out of college, but personally I think it's the deadness that would bother me." Sen in fact refers to the freedom to survive, not to the freedom that survival brings, but his wish to bring so much under the label of freedom can cause confusion of this sort. And what of the right to survive?

2 "Practical reason" refers to the reasoning in preparing for and deciding on actions and practices.

${ }^{3}$ In the language of freedom/capability as the range of real opportunities to get valued benefits, the issue of excess freedom hardly seems to arise. Sen does direct us to look at valued positive freedom, the holding of valuable options, but in practice a presumption can easily enter that more freedom ("real" freedom) is always good.

${ }^{4}$ In IDEA (2001), Manabi Majumdar, for example, signals a lack of attention to pro-active public action plans to deal with religious fundamentalism; Roberto Gargarella argues that Nussbaum has not offered sufficient support for her claims that her account of priorities applies to all women; and Xiaorong Li proposes that Nussbaum's capability approach shares some fundamental shortcomings with a human rights approach.

${ }^{5}$ Drèze and Sen have now reduced freedom's status somewhat to "among the principal means as well as the primary ends" of development (2002: 4). Here we have discussed Sen's emphasis in Development as Freedom, which has been translated into many languages and achieved remarkable sales. 


\section{REFERENCES}

Anderson, Elizabeth. 1993. Value in Ethics and Economics. Cambridge, MA: Harvard University. Press.

Badgett, Lee and Nancy Folbre. 1999. "Assigning Care: Gender Norms and Economic Outcomes." International Labor Review 138 (3): 311-26.

Bruyn-Hundt, Marga. 1996. The Economics of Unpaid Work. Amsterdam: Thesis Publishers.

Connolly, William. 1983. The Terms of Political Discourse ( ${ }^{\text {nd }}$ edition). Oxford: Martin Robertson.

Crocker, David A. 1995. "Functioning and Capability: The Foundations of Sen's and Nussbaum's Development Ethics," in Martha Nussbaum and Jonathan Glover (eds.), pp. 153-198.

Dawson, Graham, and Sue Hatt. 2000. Market, State and Feminism. The Economics of Feminist Policy. Cheltenham: Edward Elgar.

Deneulin, Severine. 2003 (Forthcoming). "Beyond Individual Freedom and Agency: The Role of Structures of Living Together in Sen's Capability Approach to Development", in Sabina Alkire, Flavio Comim and Mozaffar Qizilbash (eds.), Justice and Poverty: Examining Sen's Capability Approach, Cambridge: Cambridge University Press.

Drèze, Jean, and Amartya Sen. 2002. India: Development and Participation. Delhi: Oxford University Press.

Elson, Diane (ed.). 1995. Male Bias in Economic Development. Manchester: University of Manchester Press.

Elson, Diane and Nilufer Cagatay. 2000. "The Social Content of Macro Economic Policies.” World Development 28 (7): 1347-64.

England, Paula. 1993. "The Separative Self: Androcentric Bias in Neoclassical Assumptions," in Marianne Ferber and Julie Nelson (eds.), pp. 37-53.

Ferber, Marianne and Julie Nelson (eds.). 1993. Beyond Economic Man. Feminist Theory and Economics. Chicago: University of Chicago Press.

Folbre, Nancy and Thomas Weisskopf. 1998. "Did Father Know Best? Families, Markets, and the Supply of Caring Labor," in Avner Ben-Ner and Louis Putterman (eds.) Economics, Values and Organization, pp. 171-205. Cambridge: Cambridge University Press.

Folbre, Nancy and Julie Nelson. 2000. "For Love or Money-Or Both?” Journal of Economic Perspectives 14(4): 123-40.

Friedman, Milton and Rose Friedman. 1962. Capitalism and Freedom. Chicago: University of Chicago Press.

- $\quad$ 1980. Free to Choose. New York: Harcourt Brace Jovanovich.

Gasper, Des 1993. "Entitlements Analysis - Relating Concepts and Contexts". Development and Change 24(4), 679-718.

2000. "Development as Freedom: Taking Economics Beyond Commodities - The Cautious Boldness of Amartya Sen." Journal of International Development 12 (7): 989-1001.

- 2002. "Is Sen's Capability Approach an Adequate Basis for a Theory of Human Development?" Review of Political Economy14 (4): 435-461

Hamilton, Lawrence. 1999. "A Theory of True Interests in the Work of Amartya Sen." Government and Opposition 34 (4): 516-546.

Hewitson, Gillian. 1999. Feminist Economics. Interrogating the Masculinity of Rational Economic Man. Cheltenham: Edward Elgar.

IDEA. 2001. Symposium on Women and Human Development by Martha Nussbaum (2000). International Development Ethics Association, http://www.development-ethics.org, Reports section.

Kabeer, Naila. 1994. Reversed Realities. Gender Hierarchies in Development Thought. London: Verso.

Kolm, Serge-Christophe. 1998. "The Values of Freedom," in Jean-Francois Laslier, Marc Fleurbaey, Nicolas Gravel, and Alain Trannoy (eds.) Freedom in Economics. New Perspectives in Normative Analysis. London: Routledge, pp. 17-44.

Laslier, Francois, Marc Fleurbaey, Nicolas Gravel, and Alain Trannoy. 1998. Freedom in Economics. New Perspectives in Normative Analysis. London: Routledge.

MacCallum, Gerald. 1967. "Negative and Positive Freedom." Philosophical Review 76: 312-334. 
Nelson, Julie. 1993. "Value Free or Valueless? Notes on the Pursuit of Detachment in Economics." History of Political Economy 25 (1): 121-45.

- $\quad$ 1996. Feminism, Objectivity and Economics. London: Routledge.

Nussbaum, Martha. 1995. "Human Capabilities, Female Human Beings," in Martha Nussbaum and Jonathan Glover, (eds.) Women, Culture and Development: A Study of Human Capabilities. Oxford: Clarendon Press, pp. 61-104.

- $\quad$ 1999. "Women and Equality: The Capabilities Approach". International Labor Review 138 (3): 227-245.

- 2000. Women and Human Development. The Capabilities Approach. Cambridge: Cambridge University Press.

- 2001. Upheavals of Thought: the Intelligence of Emotions. Cambridge: Cambridge University Press.

- $\quad$ 2003. "Capabilities as Fundamental Entitlements: Sen and Social Justice." Feminist Economics $\mathrm{x}(\mathrm{y})$ :

Nussbaum, Martha and Jonathan Glover (eds.). 1995. Women, Culture and Development. A Study of Human Capabilities. Oxford: Clarendon Press.

Peacock, Alan. 1997. The Political Economy of Economic Freedom. Cheltenham: Edward Elgar.

Peter, Fabienne. 2001. "Review of Martha Nussbaum's Women and Human Development". Feminist Economics 7(2): 131-5.

Robeyns, Ingrid. 2001. "Sen's Capability Approach and Feminist Concerns." Paper to conference on Sen's capability approach. University of Cambridge, June 2001.

Seabright, Paul. 2001. "The Road Upward.” New York Review of Books, March 29.

Sen, Amartya. 1977. "Rational Fools: A Critique of the Behavioral Foundations of Economic Theory." Philosophy and Public Affairs 6 (4): 317-44.

- 1981a. Poverty and Famines: an Essay on Entitlement and Deprivation. Oxford: Oxford University Press.

- $\quad$ 1981b. "Rights and Agency." Philosophy and Public Affairs 11 (2): 3-39.

- 1984a. "Family and Food: Sex Bias in Poverty" in Amartya Sen Resources, Values and Development, pp. 346-68. Cambridge (Mass.): Harvard University Press.

- $\quad$ 1984b. "Poor, Relatively Speaking" in Amartya Sen Resources, Values and Development, pp. 325345. Cambridge (Mass.): Harvard University Press.

- $\quad$ 1985. Commodities and Capabilities. Amsterdam: North Holland.

- $\quad$ 1987. On Ethics and Economics. Oxford: Blackwell.

- $\quad$ 1989. "Food and Freedom." World Development 17 (6): 769-81.

- $\quad$ 1995. "The Formulation of Rational Choice." American Economic Review 84 (2): 385-90.

- $\quad$ 1998. "Human Development and Financial Conservatism." World Development 26 (4): 733-42. 1999. Development as Freedom. New York: Oxford University Press.

Silva Leander, Sebastian. 2001. "Sen and Kant on Freedom and Progress." Unpublished paper. Oxford University.

Staveren, Irene van. 2001. The Values of Economics. An Aristotelian Perspective. London: Routledge.

Tronto, Joan. 1993. Moral Boundaries. A Political Argument for an Ethic of Care. London: Routledge.

Truong, Thanh-Dam, 1997. "Gender and Human Development: a Feminist Perspective". Gender, Technology and Development 1 (3): 349-70.

UNDP. 1995. Human Development Report 1995. Oxford: Oxford University Press.

Walzer, Michael. 1983. Spheres of Justice. Oxford: Blackwell.

Williams, Bernard. 2001. "From Freedom to Liberty: The Construction of a Political Value". Philosophy and Public Affairs 30 (1): 3-26. 